\title{
Caloric Restriction Increases Learning Consolidation and Facilitates Synaptic Plasticity through Mechanisms Dependent on NR2B Subunits of the NMDA Receptor
}

\author{
Ángela Fontán-Lozano, ${ }^{1}$ José Luis Sáez-Cassanelli, ${ }^{1}$ Mari Carmen Inda, ${ }^{1}$ Mercedes de los Santos-Arteaga, ${ }^{1}$ \\ Sergio Antonio Sierra-Domínguez, ${ }^{1}$ Guillermo López-Lluch, ${ }^{2}$ José María Delgado-García, ${ }^{1}$ and Ángel Manuel Carrión ${ }^{1}$ \\ ${ }^{1}$ División de Neurociencias and ${ }^{2}$ Área de Biología Celular, Universidad Pablo de Olavide de Sevilla, 41013 Sevilla, Spain
}

One of the main focal points of aging research is the search for treatments that will prevent or ameliorate the learning and memory deficiencies associated with aging. Here we have examined the effects of maintaining mature mice on a long-term intermittent fasting diet (L-IFD). We found that L-IFD enhances learning and consolidation processes. We also assessed the long-term changes in synaptic efficiency in these animals. L-IFD mice showed an increase in low-theta-band oscillations, paired-pulse facilitation, and facilitation of long-term synaptic plasticity in the hippocampus with respect to mice fed ad libitum. In addition, we found an increase in the expression of the NMDA receptor subunit NR2B in some brain areas of L-IFD mice. Specific antagonism of this subunit in the hippocampus reversed the beneficial effects of L-IFD. These data provide a molecular and cellular mechanism by which L-IFD may enhance cognition, ameliorating some aging-associated cognitive deficits.

Key words: intermittent fasting diet; learning; consolidation; hippocampus; perirhinal cortex; NMDA receptors; long-term potentiation

\section{Introduction}

Aging is associated with impairments in learning and memory. Anatomical and electrophysiological studies indicate that the hippocampus of aged rodents sustains a loss of synapses, a decrease in NMDA receptor (NMDAR) responses, and alterations in calcium homeostasis. These changes may contribute to the observed age-related impairments in synaptic plasticity and in learning and memory processes (Rosenzweig and Barnes, 2003). Hence, an important aspect of aging research has been the quest for treatments preventing or ameliorating memory deficits associated with aging.

It has been proposed that a moderate reduction in caloric intake [caloric restriction (CR)] might slow aging, reduce agerelated chronic diseases, and extend the life span (Weindruch and Walford, 1988; Lane et al., 1999; Lin et al., 2000; Masoro, 2000; Stern et al., 2001; Berrigan et al., 2002; Barger et al., 2003; Hursting et al., 2003; Ingram et al., 2004; Roth et al., 2004). Moreover, studies in humans indicate that some metabolic markers of aging improve with CR diets (Walford et al., 1992, 2002; Verdery and Walford, 1998; Heilbronn and Ravussin, 2003).

Long-term plastic synaptic changes have been postulated as a

\footnotetext{
Received April 3, 2006; revised Aug. 6, 2007; accepted Aug. 8, 2007.

This work was supported by grants from the Spanish Agency for International Cooperation, the Junta de Andalucía (CVI-122), CAMD2005, and the Dirección General de Investigación Ciencia y Técnica (BFU2005-01024). We thank Drs. A. Múnera and M. Sefton for critical reading and editorial assistance with this manuscript. We also thank M. C. Sutil, M. D. Marín, and M. Cadena for technical assistance with animal handling.

Correspondence should be addressed to Dr. Ángel M. Carrión, División de Neurociencias, Universidad Pablo de Olavide, Carretera de Utrera Kilómetro 1, 41013 Sevilla, Spain. E-mail: amancar@upo.es.

M. C. Inda's present address: Instituto de Neurobiología Ramón y Cajal, Avenida Dr. Arce37, 28002 Madrid, Spain. D0I:10.1523/JNEUROSCI.2757-07.2007

Copyright $\odot 2007$ Society for Neuroscience $\quad$ 0270-6474/07/2710185-11\$15.00/0
}

putative building block for memory formation (Daoudal and Debanne, 2003; Gruart et al., 2006), and long-term potentiation (LTP) could be a model of neural changes underlying learning mechanisms. In the CA1 region of the hippocampus, the opening of NMDARs seems to be necessary for memory formation (Bliss et al., 2003). Functional NMDAR complexes are composed of NR1 and NR2 subunits and of adaptor, signaling, cytoskeletal, and cell-adhesion proteins (Husi et al., 2000; Walikonis et al., 2000). It is known that the NR2A and NR2B subunits predominate in the adult forebrain (Monyer et al., 1994; Loftis and Janowsky, 2003), although many brain regions contain predominantly NR2A subunits (e.g., the hippocampus). Both NR2A and NR2B subunits play important roles in LTP and associative learning (Sakimura et al., 1995; Kim et al., 2005; ValenzuelaHarrington et al., 2007). During aging, a switch from NR2B to NR2A in NMDARs is commonly observed in many brain regions (Monyer et al., 1994; Sheng et al., 1994), and it may contribute to a reduction in adult brain plasticity (Barria and Malinow, 2005).

It is well established that CR decreases aging-related deficiencies in cognitive processes (Idrobo et al., 1987; Ingram et al., 1987; Stewart et al., 1989; Pitsikas and Algeri, 1992). However, the molecular and cellular bases of these effects remain unclear. Here, we show that intermittent fasting diet (IFD; a variant of CR) enhances learning and memory processes in mature mice when compared with mice fed ad libitum (AL). Hippocampal activity in IFD mice shows an increase in low-theta-band oscillations, paired-pulse facilitation (PPF), and enhanced synaptic plasticity. Some brain areas, including the hippocampus, of IFD mice displayed an increase in NR2B subunit of NMDAR expression when compared with those from AL mice. Finally, infusion of NR2B antagonist in the hippocampus reversed the IFD-induced en- 
hancement of cognitive processes and hippocampal function. These results suggest that the increase in NR2B could be responsible for IFD-induced improvement in cognition.

\section{Materials and Methods}

Animals

Eight-week-old male Swiss mice, weighing between 25 and $30 \mathrm{~g}$, were maintained under a $12 \mathrm{~h}$ light/dark cycle. The animals were divided into two groups, one of which was fed ad libitum and the other of which was fed on alternate days (i.e., with dietary restriction). The mice were maintained on this feeding regimen for 6-8 months [long-term IFD (L-IFD)]. Total intake (weekly) and activity were similar to those described previously (Anson et al., 2003; de los Santos-Arteaga et al., 2003). Mice were kept to the same diet schedule during behavioral and electrophysiology experiments. All behavioral and electrophysiological studies were conducted in accordance with the guidelines of the European Union Council (86/609/EU) and following Spanish regulations for the use of laboratory animals in chronic experiments (BOE 67/8509-12, 1988). Furthermore, all the experiments were approved by the local institutional animal care committee.

\section{Drug administration}

$R$-( $R, S)$ - $\alpha$-(4-hydroxyphenyl)- $\beta$-methyl-4-(phenylmethyl)-1piperidine propranol (Ro25-6981) (Sigma-Aldrich, Madrid, Spain), a potent antagonist of the NR2B subunit, was dissolved in DMSO (vehicle) at a concentration of $5 \mathrm{mg} / \mathrm{ml}$. Mice received subcutaneous injections of Ro25-6981 at $5 \mathrm{mg} / \mathrm{kg}$ or an equivalent volume of vehicle. For the local administration of the drug, the animals were anesthetized, secured in a stereotaxic frame, and implanted bilaterally with guide cannulas directed at the hippocampus or at the perirhinal cortex. Two stainless-steel guide cannulas were implanted through burr holes in the skull, using the following coordinates (relative to bregma): for hippocampus, anteroposterior (AP), $-2.2 \mathrm{~mm}$; lateral (L), $\pm 1.5 \mathrm{~mm}$; and ventral $(\mathrm{V}),-1.1 \mathrm{~mm}$; for perirhinal cortex, AP, $-3.4 \mathrm{~mm} ; \mathrm{L}, \pm 4 \mathrm{~mm}$; and $\mathrm{V},-1.8 \mathrm{~mm}$. The guide cannulas were anchored to the skull by two stainless-steel skull screws and dental cement. Between infusions, the cannulas were closed by dummy cannulas. Mice were allowed to recover for at least $10 \mathrm{~d}$ before habituation to the testing arena began. Ten minutes before behavior tests, $0.5 \mu \mathrm{l}$ of a $50 \mu \mathrm{M}$ solution of Ro25-6981 was microinjected over $60 \mathrm{~s}$ through each cannula, and the infusion cannulas were left for an additional $60 \mathrm{~s}$ to minimize back-flow. Cannula placement was verified postmortem: 2-4 h after the last behavioral test, mice were killed and brains were processed for Nissl staining. Only data from animals with correct cannula implants were included in statistical analyses.

\section{Behavioral learning studies}

The motor learning test. The rotarod (Ugo Basile Biological Research Apparatus, Comerio, Italy) consists of a gritted plastic roller $(3 \mathrm{~cm}$ in diameter, $6 \mathrm{~cm}$ long) flanked by two round plates $(30 \mathrm{~cm}$ in diameter) to prevent the animal from escaping. To habituate mice to the rotarod, the animals were placed on the roller at $20 \mathrm{rpm}$ for $300 \mathrm{~s}$. To assay motor learning, animals were subjected to one daily session of $300 \mathrm{~s}$ on 4 consecutive days, with the roller being driven at $60 \mathrm{rpm}$. The number of trials required for the animals to complete $300 \mathrm{~s}$ on the cylinder and the maximum time they remained on it were measured in each session.

Operant conditioning. Training was performed using a Skinner's box (Cibertec, Madrid, Spain). Two weeks before training, all the mice were handled daily. The weight of the animals $10 \mathrm{~d}$ before training was used as a baseline for the food restriction regimen. Animals were weighed daily to maintain their body weight at $85 \%$ of the baseline. Mice were assayed only on alternative days, so as not to disturb the IFD regimen.

Initially, all mice received a $10 \mathrm{~d}$ training to associate lever pressing with food-pellet reinforcements. Once they had acquired this association, mice were submitted to a $12 \mathrm{~s}$ fixed-interval reinforcement schedule during $8 \mathrm{~d}$ (a single reinforcement was delivered if the mouse pressed the bar at least once during the $12 \mathrm{~s}$ interval). In this schedule, reinforced lever pressures were considered conditioned if, and only if, they occurred during the second half of the selected interval (i.e., between seconds 7 and 12).
Eyeblink classical conditioning. For recording and stimulating purposes, a low-weight, four-channel wire was connected to the socket implanted on the animal's head. Conditioned and unconditioned stimuli (CSs and USs, respectively) consisted of 50 and $500 \mu$ s cathodic electrical pulses delivered through the pair of electrodes implanted in the right upper periorbital region, close to the supraorbital nerve. CS and US intensities (in $\mathrm{mA}$ ) were determined experimentally for each animal before beginning the training, and selected values were not modified across conditioning. CS and US intensities were defined according to criteria described previously (Inda et al., 2005). A stimulus-free interval of 250 ms was interposed between the end of the CS and the onset of the US. Eyelid responses were monitored from the electromyographic activity of the orbicularis oculi muscle, recorded through the second pair of implanted eyelid electrodes. Additional details of this experimental paradigm have been presented previously (Domínguez-del-Toro et al., 2004; Inda et al., 2005).

The complete classical conditioning training consisted of 10 daily 40 trial sessions: three habituation (CS-alone trials) and seven conditioning (paired CS-US trials) sessions. The interval between trials was randomized between 25 and $35 \mathrm{~s}$, and in all behavioral experiments, six to eight animals per group were used.

Object recognition test. Mice were tested in a rectangular arena $(55 \times$ $40 \times 40 \mathrm{~cm}$ ) located in a room with dim lighting and constant background noise. In the object recognition protocol, two different objects were placed in the arena during the training phase. After a delay of 1 or $24 \mathrm{~h}$, one object was changed to a novel object. The aim was to test the animal's memory of the original objects by measuring the amount of time spent exploring the novel object versus the familiar one. Selected objects consisted of plastic pieces with different forms and were thoroughly cleansed between trials to ensure the absence of olfactory cues. Before the experiment, mice were habituated to the arena in the absence of objects for $20 \mathrm{~min}$ each day over $2 \mathrm{~d}$; on the day of testing, mice were permitted either 5 or $15 \mathrm{~min}$ to explore the two objects. Retention tests were performed either 1 or $24 \mathrm{~h}$ later by placing the mice back in the arena for a 10 min session and by randomly exchanging one of the familiar objects with a novel one. The time spent exploring each object was recorded, and the relative exploration of the novel object was expressed by a discrimination index [DI $\left.=\left(t_{\text {novel }}-t_{\text {familiar }}\right) /\left(t_{\text {novel }}+t_{\text {familiar }}\right)\right]$. The criteria for exploration were based strictly on active exploration, during which the mouse had both forelimbs within a circle of $1.5 \mathrm{~cm}$ around the object, with its head oriented toward it, or was touching it with its vibrissae.

\section{Analysis of $m R N A$ by reverse transcription-PCR}

Total RNA from brain tissue was extracted using Tripure reagent (Roche, Basel, Switzerland). For reverse transcription (RT)-PCR, the primers were the same as those used by Sheng et al. (1994). Arbitrary units of the ordinate axes in Figure 4 were computed as the ratio between the optical density of the gene under study in the 30th cycle of amplification and that of the glyceraldehyde-3-phosphate dehydrogenase (GAPDH) gene in the 15 th cycle.

\section{Tissue preparation and immunohistochemistry}

To analyze the expression of the NR2B subunit, five mice were taken from each experimental group and killed by decapitation. The brain was removed and placed on an ice-cold plate, and the tissue was fixed by immersion in $4 \%$ paraformaldehyde in PBS for $24 \mathrm{~h}$ at $4^{\circ} \mathrm{C}$. The tissue was cryoprotected in $30 \%$ sucrose-PBS for $2 \mathrm{~d}$ at $4^{\circ} \mathrm{C}$, embedded in $30 \%$ sucrose, and then maintained at $4^{\circ} \mathrm{C}$ until cryotome sectioning. Coronal brain sections $(50 \mu \mathrm{m})$ were processed for free-floating immunohistochemistry (de los Santos-Arteaga et al., 2003), using the specific antiserum raised against the NR2B subunit at a 1:250 dilution (AB1557P; Millipore, Billerica, MA). To quantify the expression of this subunit, the optical density of different cerebral areas was measured using ImageJ software. To minimize the variability of this technique, at least five sections for animal were analyzed in at least two independent immunohistochemistry stains. 


\section{Electrophysiological recordings}

Animals were anesthetized with $0.8-3 \%$ halothane delivered through a home-made mask (AstraZeneca, Madrid, Spain). Halothane was administered from a calibrated Fluotec 5 (Fluotec-Ohmeda, Tewksbury, MA) vaporizer at a flow rate of $1-4 \mathrm{~L} / \mathrm{min}$ oxygen. Once anesthetized, the animals were implanted with electrodes made of $50 \mu \mathrm{m}$ Teflon-coated tungsten wires (Advent Research Materials, Eynsham, UK). With the help of stereotaxic coordinates (Paxinos and Franklin, 2001), bipolar stimulating electrodes were implanted on the Schaffer's collateral-commissural pathway of the dorsal hippocampus (from bregma, AP, $1.5 \mathrm{~mm}$; $\mathrm{L}, 2.2 \mathrm{~mm}$; depth from brain surface, $1.0-1.5 \mathrm{~mm}$ ). Two recording electrodes were also implanted in the ipsilateral stratum radiatum underneath the CA1 area (from bregma, AP, 2.2; L, $1.2 \mathrm{~mm}$; depth from brain surface, $1.0-1.5 \mathrm{~mm}$ ). The final position of the hippocampal stimulating and recording electrodes was determined by on-line recording procedures (see below). The four wires were connected to a four-pin socket (RS-Amidata, Madrid, Spain), and the ground wire was connected to the recording system with a single wire. A $0.1 \mathrm{~mm}$ bare silver wire was fixed to the skull as a ground. Sockets were fixed to the skull with the help of two small screws and dental cement [for more details, see Gruart et al. (2006)]. Recordings were performed using Grass P511 differential amplifiers with a bandwidth of $0.1 \mathrm{~Hz}$ to $10 \mathrm{kHz}$ (Grass-Telefactor, West Warwick, RI).

All of the in vivo recordings were performed at least $7 \mathrm{~d}$ after surgery. To evoke LTP, each animal received five-pulse trains $(200 \mathrm{~Hz}, 100 \mathrm{~ms})$ at a rate of $1 / \mathrm{s}$. This protocol was administered either once or a total of three times at intervals of $1 \mathrm{~min}$. Hippocampal activity was stored digitally on a computer through an analog/digital converter (1401 Plus; Cambridge Electronic Design, Cambridge, UK) at a sampling frequency of 11-22 $\mathrm{kHz}$ and with an amplitude resolution of 12 bits. Computer programs (Spike 2 and SIGAVG; Cambridge Electronic Design) were adapted to represent extracellular synaptic field potential (fEPSP) recordings. The slope of the evoked fEPSPs was collected as the first derivative (i.e., $\mathrm{V} / \mathrm{s}$ ) of fEPSP records (V). For this, five successive evoked field synaptic potentials at intervals of $5 \mathrm{~min}$ were averaged, and the mean value of the slope was determined for the rise-time period (i.e., the period of the slope between the initial $10 \%$ and the final $10 \%$ of the evoked field potential).

The power spectrum of the hippocampal field activity was calculated using the fast Fourier transformation with a Hanning window. This parameter was expressed as the relative power and averaged across each session. The average was analyzed and compared using the wide-band model, considering the following bands: low theta $(2-4 \mathrm{~Hz})$ and theta (4-9 Hz).

For paired-pulse facilitation, two stimuli of an intensity that evoked $35-40 \%$ of the maximum response of fEPSP were delivered with an interstimulus interval of $20-200 \mathrm{~ms}$. The percentage of facilitation was calculated as (slope S2/slope S1) $\times 100$. Facilitation was considered $100 \%$ in the interstimulus interval with maximum facilitation, and the other intervals were normalized with respect to the maximum facilitation interval.

\section{Statistical analysis}

The results were processed for statistical analysis using the SPSS for Windows package (SPSS, Chicago, IL). Unless otherwise indicated, data are represented by the mean \pm SEM. Collected data were analyzed using a two-way ANOVA test with time or session as the repeated measure, coupled with a contrast analysis when appropriate. One-way ANOVA allowed the statistical differences between the groups to be checked.

\section{Results}

\section{L-IFD increases cognitive function in mature mice}

$\mathrm{CR}$ ameliorates learning deficiencies in aging rodents (Idrobo et al., 1987; Pitsikas and Algeri, 1992). Some studies report that IFD mimics many of the biochemical aspects of CR (Anson et al., 2003; Mattson et al., 2003), but it has not been studied yet whether L-IFD in mature mice might produce beneficial effects on cognitive function. We tested L-IFD and AL mice in a battery of learning and memory tasks. Initially, we assessed the motor
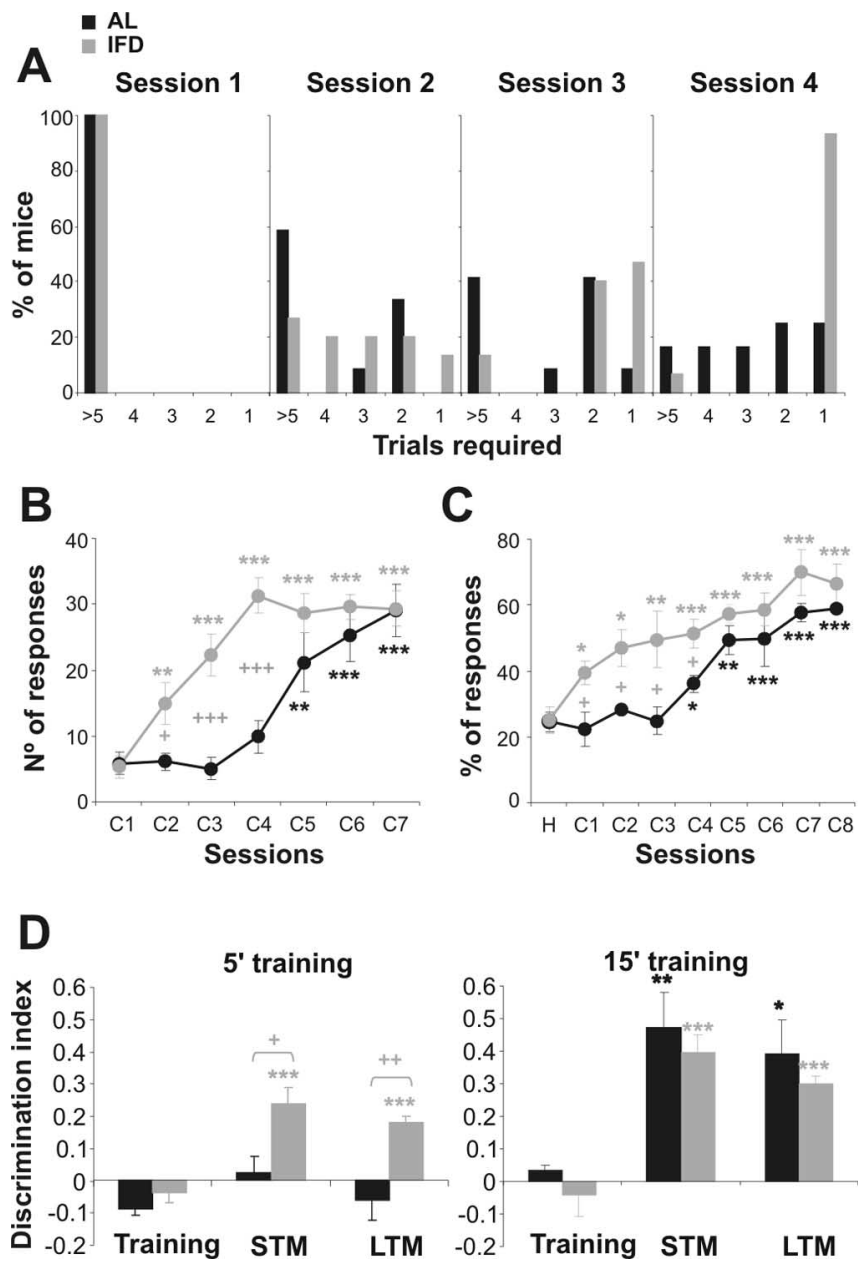

Figure 1. L-IFD induces an enhancement of learning and memory processes. $\boldsymbol{A}$, Motor learning was assayed using a rotarod over four sessions. The percentage of mice (ordinate) and the number of trials required (abscissa) to complete $5 \mathrm{~min}$ on a $60 \mathrm{rpm}$ rotating cylinder is shown ( $n=13$ and 14 for AL and L-IFD mice, respectively). $\boldsymbol{B}$, Number of conditioning responses per session after training in $12 \mathrm{~s}$ fixed-interval operant conditioning. $\boldsymbol{C}$, Percentage of conditioned responses per session across the whole training using a trace electrical shock-SHOCK eyeblink classical conditioning paradigm ( $n=10$ and 8 for the two groups in operant and classical conditioning, respectively). $D$, The object recognition memory test was performed for $5 \mathrm{~min}$ and 15 min training sessions ( $n=8$ for both groups). Discrimination indices during training, STM, and LTM sessions ( 1 and $24 \mathrm{~h}$ after training, respectively) are shown for each experimental procedure. Black and gray colors represent AL and L-IFD mice, respectively. ${ }^{+}$Statistical significance of AL and L-IFD mice in the same session; * statistical significance of the different session with respect to habituation in the same group. ${ }^{+, *} p \leq 0.05 ;^{++, * *} p \leq 0.01 ;^{+++, * * *} p \leq$ 0.001. H, Habituation session; (1-C8, conditioning sessions 1-8.

coordination of the mice in the rotarod test. Mature mice were given a daily session over 4 consecutive days (Fig. $1 A$ ). We determined the number of trials required for the animals to complete the session (i.e., to remain on the rotating rod for $5 \mathrm{~min}$ ). Most mice required multiple trials (more than five) on the first day, although both AL and L-IFD mice were capable of learning the task. However, by the fourth session, $93.33 \%$ of L-IFD mice completed the task in the first trial, compared with only $25 \%$ of the AL mice. Because L-IFD and AL mice showed the same body weight, muscular strength, and resistance on the rotarod (supplemental Fig. 1, available at www.jneurosci.org as supplemental material), we concluded that L-IFD mice were clearly more capable of learning this test than were AL mice.

To test associative learning in the two groups of mice, fixedinterval (12 s) operant conditioning and trace eyeblink classical 
conditioning were used (Fig. $1 B, C$ ). In both conditioning paradigms, AL and L-IFD mice learned the task in seven to eight sessions (for operant conditioning, $F_{(59,6)}=12.03, p<0.001$ and $F_{(49,6)}=13.92, p<0.001$ for AL and L-IFD mice, respectively; for eyeblink classical conditioning, $F_{(30,9)}=12.778, p<0.001$ and $F_{(39,9)}=6.19, p<0.001$ for AL and L-IFD mice, respectively). However, L-IFD mice learned the two tasks faster than did the AL mice (statistically significant differences were found in the second to fourth sessions with both conditioning protocols; $p<0.05$ ). Subsequently, we studied the possible differences between AL and L-IFD mice in object recognition memory (ORM) (Fig. 1D) using two different training protocols: after a 5 min training session, only L-IFD mice remembered the information both $1 \mathrm{~h}$ after training, reflecting short-term memory (STM; DI $=0.24 \pm 0.04$; $p<0.001$ ) (Fig. $1 D$, left plot), and $24 \mathrm{~h}$ after training (DI $=$ $0.179 \pm 0.02 ; p<0.001$ ), reflecting long-term memory (LTM). In contrast, when a $15 \mathrm{~min}$ training protocol was performed, no differences were observed between AL and L-IFD mice (Fig. $1 D$, right plot). Furthermore, the exploration times in short and long training for the object recognition test were not different for L-IFD mice with respect to AL ones (see supplemental Table 1, available at www.jneurosci.org as supplemental material). Taking these data together, we concluded that learning and memory processes were enhanced in mature mice that underwent L-IFD with respect to mature mice fed $\mathrm{AL}$, although the maximum learning capacity of AL and L-IFD mice was similar.

\section{L-IFD provokes changes in the basal activity of the hippocampus}

The hippocampus is a cortical region involved in information processing and memory consolidation (Squire and ZolaMorgan, 1991). To study the basal activity in the hippocampus, we implanted a bipolar stimulation electrode in the Schaffer's collateral and a recording electrode in apical dendrites of the CA1 field (Fig. 2A). The background hippocampal activity recorded in mature AL and L-IFD mice showed no differences in the amplitudes of the theta rhythm during exploratory behavior (58.45 \pm $3.88 \%$ and $58.6 \pm 4.13 \%$ of the relative spectrum in $\mathrm{AL}$ and L-IFD mice, respectively; $p=0.95)($ Fig. $2 A-C)$. However, we did detect an increase in the low-theta-band oscillations (from 1 to 4 $\mathrm{Hz})$ in L-IFD mice $(24.7 \pm 0.43 \%$, against $18.86 \pm 1.7 \%$ in $\mathrm{AL}$ mice; $p<0.001)$. Furthermore, we performed PPF with interpulse intervals ranging from 20 to $200 \mathrm{~ms}$, to study the basal synaptic state (Fig. 2D). In AL mice, the PPF was maximum at an interpulse interval of $50 \mathrm{~ms}(97.63 \pm 1.37 \%$ of maximum facilitation), and it diminished at shorter and longer interpulse intervals. In contrast, L-IFD mice did not show a decrease in the PPF at any of the interpulse intervals examined $(96.013 \pm 2.28,92.76 \pm$ $3.4,94.511 \pm 3.324$, and $90.56 \pm 2.04 \%$ maximum paired-pulse facilitation at interpulse intervals of $20,50,100$, and $200 \mathrm{~ms}$, respectively; $\left.F_{(20,3)}=0.686 ; p=0.57\right)$, suggesting that the CA3CA1 synapse was functionally affected in L-IFD mice. This alteration may indicate that neuronal excitability to a second pulse is augmented in hippocampal neurons in mice subjected to L-IFD with respect to AL mice (percentage of maximum paired-pulse facilitation in interpulse intervals of $200 \mathrm{~ms}$ was $49.70 \pm 9.61$ and $84.63 \pm 5.11$ in AL and IFD mice respectively; $p<0.001$ ).

\section{Long-term changes in synaptic efficacy are facilitated in L-IFD mice}

Because it appears that L-IFD affects functional capabilities of the CA3-CA1 synapse, we examined the effects of L-IFD on LTP in the Schaffer's collateral-CA1 synapse in behaving mice. We first
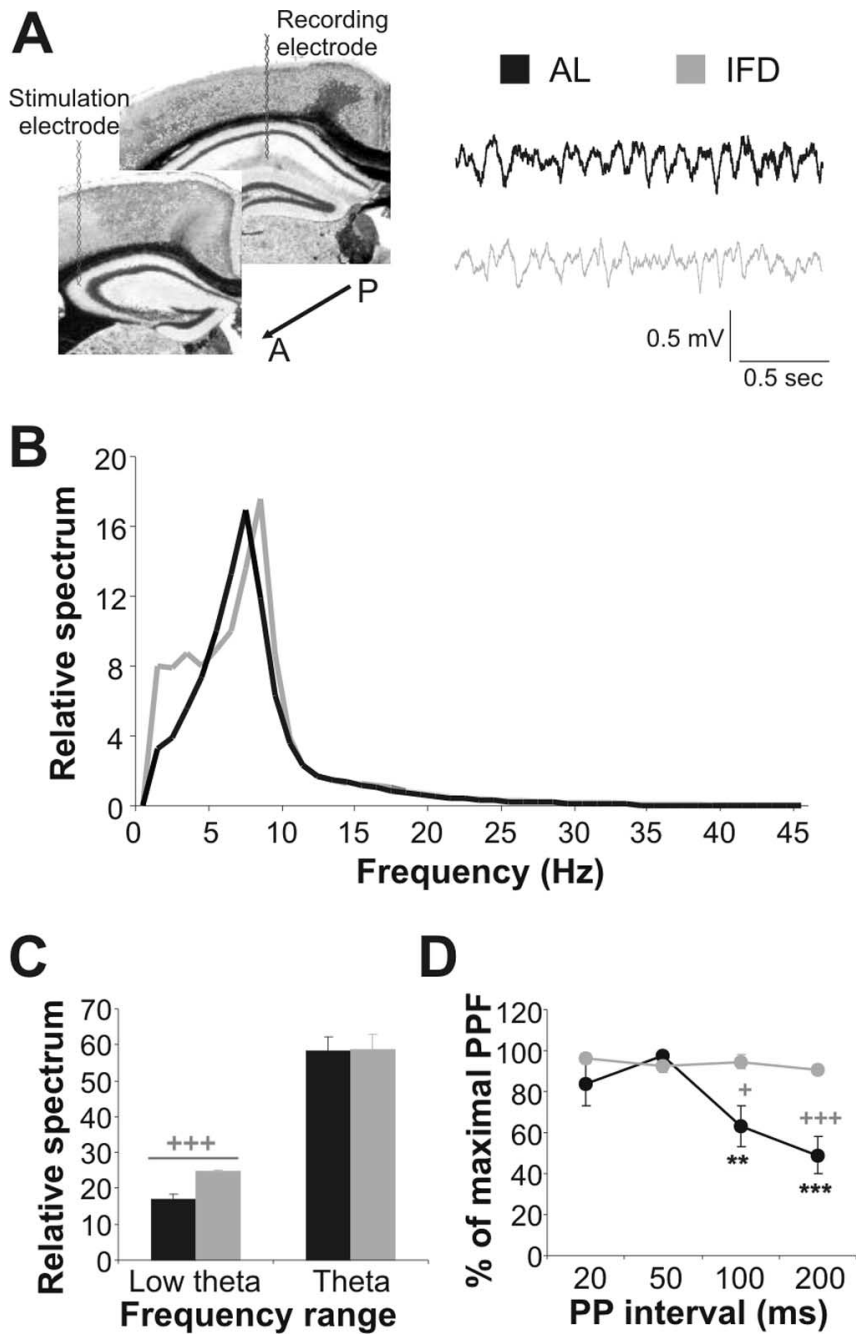

Figure 2. L-IFD induces alterations in basal electric oscillations and synaptic transmission in the hippocampus. $A$, Schematic representation of sites at which the stimulating and recording electrodes, aimed to activate $\mathrm{CA3}-\mathrm{CA1}$ synapses in the hippocampus, were implanted. Two seconds of basal electrocorticogram recordings, from two selected AL and L-IFD mice, are also shown (black for AL and gray for L-IFD mice). A, Anterior; $P$, posterior. $B$, Mean power spectra of hippocampal local field activity recorded from the CA1 pyramidal layer of AL and L-IFD mice during exploratory behavior. C, Relative spectrum quantification (mean \pm SEM) in the lowtheta and theta ranges for AL and L-IFD mice. D, Basal neurotransmission was measured by paired pulses with interpulse intervals from 20 to $200 \mathrm{~ms}$. The percentage of maximum pairedpulse facilitation in each interpulse interval in AL and L-IFD mice is represented ( $n=6$ for each group). ${ }^{+}$Statistical significance of AL and L-IFD mice in the same session; * statistical significance of the different session with respect to $50 \mathrm{~ms}$ paired pulse (PP) interval in the same group. ${ }^{+} p \leq 0.05 ;{ }^{* *} p \leq 0.01 ;{ }^{+++, * * *} p \leq 0.001$.

used high-frequency stimulation (HFS; five-pulse trains of 200 $\mathrm{Hz}, 100 \mathrm{~ms}$, at a rate of $1 / \mathrm{s}$ ) at an intensity that evoked $35-40 \%$ of the maximum response of fEPSPs. This protocol did not produce any short- or long-term changes in synaptic efficacy in AL mice $\left(F_{(20,3)}=0.81 ; p=0.509\right)$ (Fig. $\left.3 A, B\right)$. However, the same pattern of stimulation did produce an enhanced and sustained longlasting response in L-IFD mice (Fig. $3 A, B)\left(F_{(20,3)}=16.76 ; p<\right.$ $0.001 ; 30$ min after HFS, $137.62 \pm 4.87 \%$ for L-IFD mice and $105.32 \pm 3.16 \%$ for AL mice; $p<0.001 ; 1 \mathrm{~h}$ after HFS, $141.84 \pm$ $0.84 \%$ for L-IFD mice and $104.91 \pm 4.24 \%$ for AL mice; $p<$ $0.001 ; 2 \mathrm{~h}$ after HFS, $122.39 \pm 4.34 \%$ for L-IFD mice and $108.93 \pm 7 \%$ for AL mice; $p=0.13$ ). We also compared the CA3-CA1 synapse response in AL and L-IFD mice to repeated HFS trains, known to elicit a robust and prolonged change in 

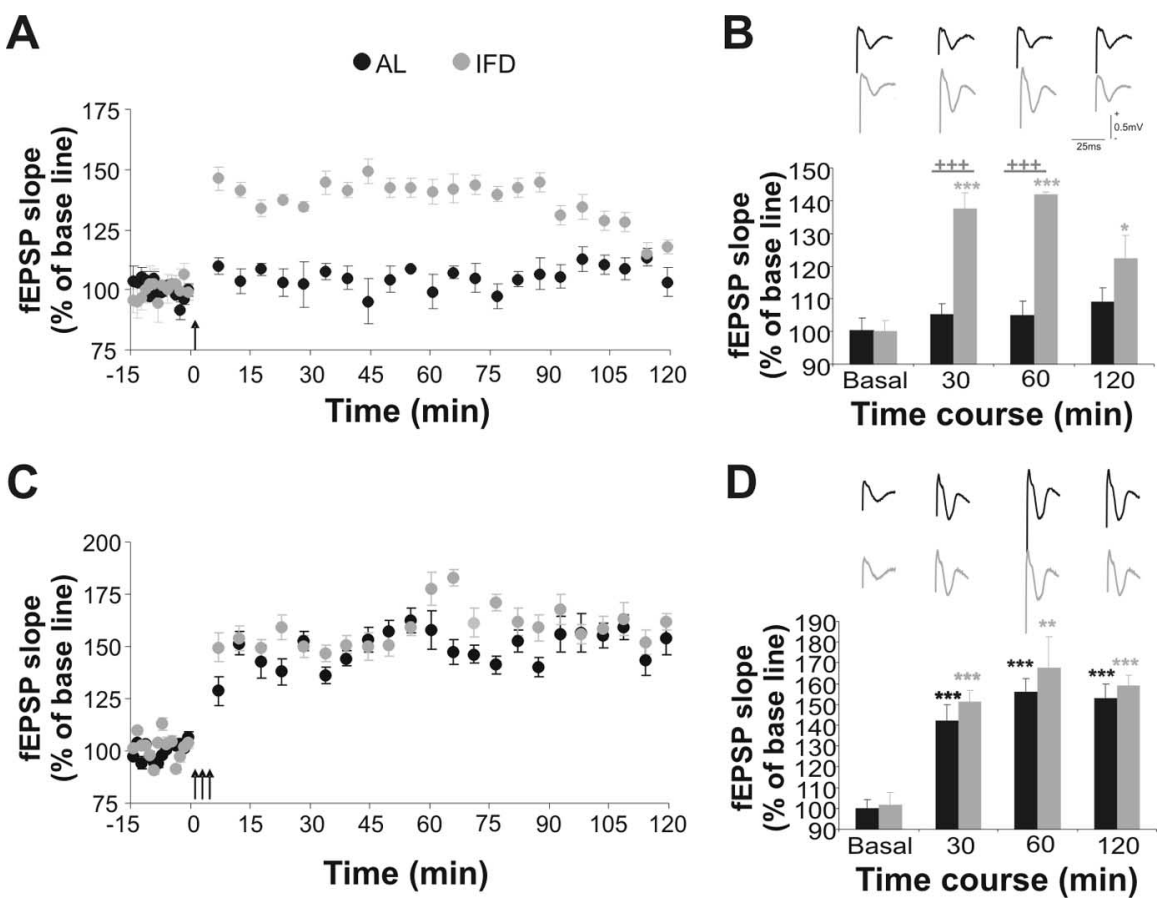

Figure 3. Early and late LTP is enhanced in L-IFD mice. $A$, A single HFS train [arrow; five pulses ( $200 \mathrm{~Hz}$, $100 \mathrm{~ms}$ ) at a rate of $1 / \mathrm{s}$ ] evoked LTP that lasts for up to $2 \mathrm{~h}$ in L-IFD mice (gray), but not in AL mice (black). $B$, Summary of the changes in fEPSP slope (mean \pm SEM) at different times after a single HFS train. Representative fEPSP recordings, collected at the same time, from AL and L-IFD mice are also shown. C, Three HFS trains (arrows) induced indistinguishable LTP (lasting $>2 \mathrm{~h}$ ) in AL and L-IFD mice. $\boldsymbol{D}$, Summary of changes in fEPSP slope (mean \pm SEM) at different times after three HFS trains. Representative fEPSP recordings, collected at the same time, in AL and L-IFD mice are also shown ( $n=6$ for each group). ${ }^{+}$Statistical significance of AL and L-IFD mice in the same session; * ${ }^{*}$ tatistical significance of the different session with respect to baseline recording in the same group. ${ }^{*} p \leq 0.05 ;{ }^{* *} p \leq 0.01 ;{ }^{+++, * * *} p \leq 0.001$.

synaptic efficacy that involves nuclear-dependent processes (Abel and Lattal, 2001; Kandel, 2001). The overall LTP produced in L-IFD mice by three HFS trains was longer and more consistent than that produced by a single HFS train (compare the $122.39 \pm 7 \%$ and $158.89 \pm 5.08 \%$ fEPSP slope in L-IFD mice $2 \mathrm{~h}$ after one or three HFS trains, respectively; $p=0.0014)$. However, this was similar to the LTP elicited by three HFS trains in AL mice (Fig. 3C,D). From these data together, we concluded that longterm synaptic plasticity evoked by HFS is facilitated in mature mice subjected to L-IFD.

\section{L-IFD provokes changes in NMDAR expression in the brain} Because NMDARs play a pivotal role in learning and long-term changes of synaptic efficacy (Huerta et al., 2000) and their subunits expression change during rodents' lifespan (Monyer et al., 1994; Sheng et al., 1994), we analyzed the expression of the predominant NR subunits in the adult forebrain by performing semiquantitative RT-PCR with specific primers for NR1, NR2A, and NR2B NMDAR subunits on tissue from the hippocampal, perirhinal, and somatosensory cortices of AL and L-IFD mature mice (Fig. 4). In the hippocampus and perirhinal cortex, we detected a significant $(p<0.01)$ increase of $3.24 \pm 0.42$ and $1.99 \pm$ 0.121 -fold, respectively, in the expression of NR2B subunits in L-IFD mice with respect to AL mice (Fig. $4 A, C$ ). We also detected an increase of $1.87 \pm 0.152$-fold in the NR1 subunit of NMDAR in the perirhinal cortex of L-IFD mice with respect to AL mice $(p<0.01)$. However, no significant differences were detected in somatosensory cortex regarding the expression of the different NMDAR subunits analyzed (Fig. $4 B$ ). The ratio of NR2B/NR2A NMDAR subunits was statistically different between L-IFD and
AL animals only in hippocampus. We also performed immunohistochemistry on the hippocampus to determine whether the expression of the NR2B subunit in L-IFD mice was generalized or local. Densitometric analysis of the immunolabeling revealed a significant increase in the accumulation of the NR2B subunit in the dentate gyrus (DG) and CA1 field, in both somatic and dendritic layers of L-IFD mice with respect to those of AL mice (Fig. $4 C)(p<0.001$ for the soma and dendrites in the CA1 field and for the soma of the DG; $p<0.01$ in the dendrites of DG neurons). All these data point to a specific increase in the NR2B subunits of synaptic and extrasynaptic NMDAR in hippocampus after L-IFD in mature mice.

The alterations in the basal activity of the hippocampus induced by L-IFD were restored by an NR2B antagonist L-IFD provoked changes in the relative spectral power of the low-theta-band oscillations in the hippocampus, as well as in paired-pulse facilitation of CA3-CA1 synapses. Furthermore, we detected alterations in the expression of the NR2B subunit of NMDAR in the hippocampus of L-IFD mice when compared with $\mathrm{AL}$ mice. Therefore, we wanted to determine whether the changes in NR2B expression were related to the changes in basal hippocampal activity observed in L-IFD mice. For this, we administered a specific antagonist for NMDARs that contain the NR2B subunit, Ro25-6981 (5 mg/kg), 30 min before recording. To test the efficiency of Ro25-6981, the same doses described above blocked learning of a 5 min training ORM task in 21-d-old mice, an age at which high levels of NR2B subunit of NMDAR are expressed (supplemental Fig. 2, available at www.jneurosci.org as supplemental material). Administration of Ro25-6981 did not alter the relative spectrum of the low-theta or theta range in $\mathrm{AL}$ mice (Fig. 5A,B). However, the NR2B antagonist restored the relative spectrum increase in the low-theta spectrum in the hippocampus of L-IFD mice (Fig. $5 A, B$ ) (relative spectrum in the low-theta range was $24.7 \pm 0.43 \%, 18.63 \pm 1 \%$, and $16.86 \pm$ $1.7 \%$ for L-IFD, L-IFD treated with Ro25-6981, and AL mice, respectively; $p<0.001$ for L-IFD against L-IFD plus Ro25-6981 mice). In contrast, Ro25-6981 administration did not affect the relative spectral power of the theta band in L-IFD mice. We also tested whether the NR2B subunit of the NMDAR was involved in the increased PPF of CA3-CA1 synapses observed in L-IFD mice. Administration of Ro25-6981 did not change the PPF at any interpulse interval tested in AL mice (Fig. 5C). In contrast, this antagonist induced a decrease in the PPF pattern when administered to L-IFD mice, reducing it closer to the levels observed in $\mathrm{AL}$ mice (Fig. 5C).

Together, these data suggest that the NR2B subunit of NMDAR could be responsible for the change in hippocampal oscillatory activity observed in L-IFD mice. However, this subunit is unlikely to be fully responsible for the altered pattern of hippocampal PPF found in these L-IFD mature mice. 
A
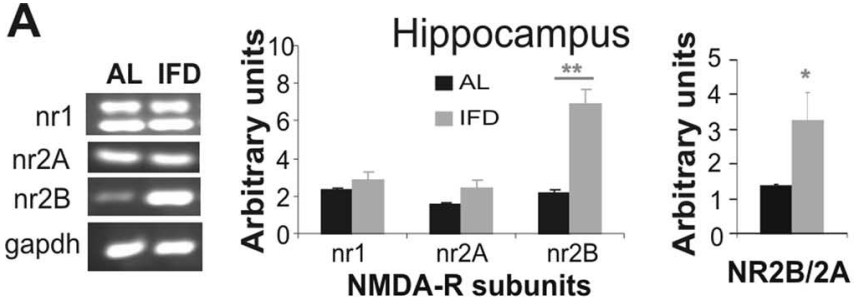

B
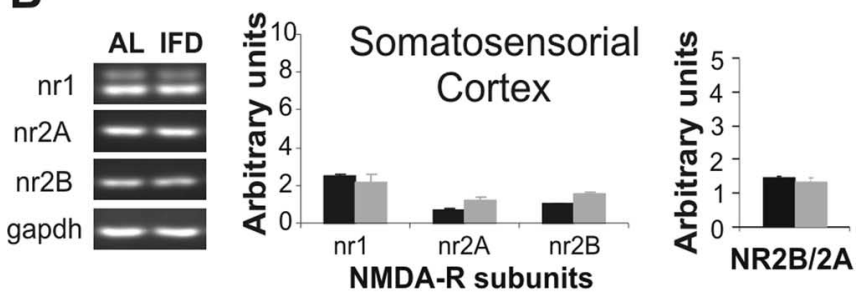

C
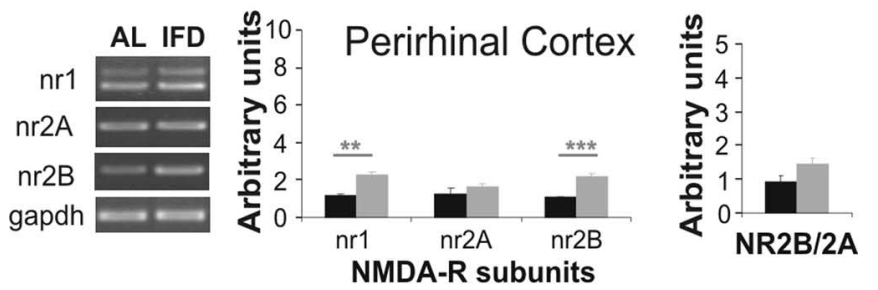

D
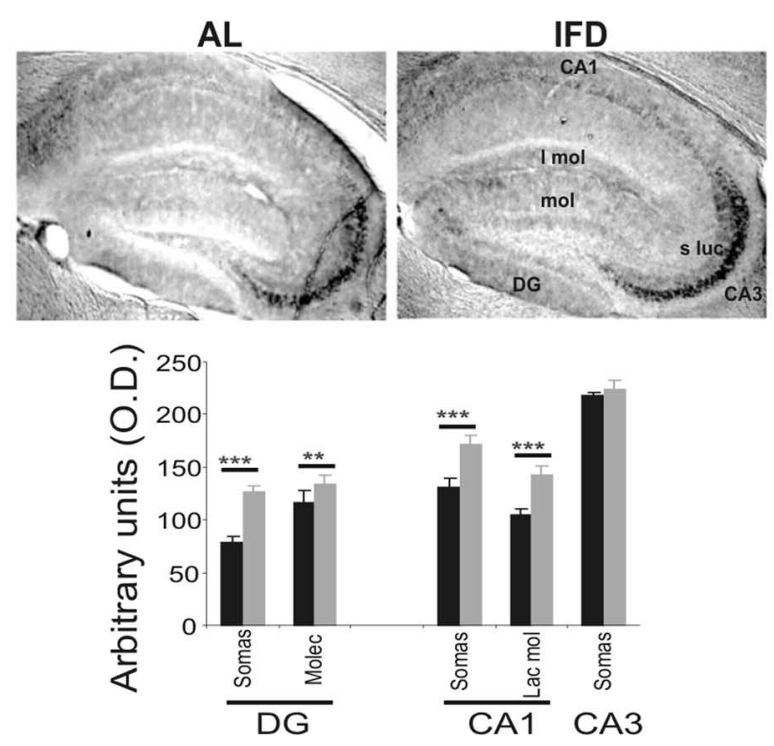

Figure 4. L-IFD induces overexpression of the NR2B subunit of NMDAR in the hippocampus. $\boldsymbol{A}-\boldsymbol{C}$, Basal expression of genes encoding different NMDAR subunits in hippocampal $(\boldsymbol{A})$, somatosensory $(\boldsymbol{B})$, and perirhinal $(\boldsymbol{C})$ cortices of AL and L-IFD mice as assessed by semiquantitative RT-PCR. The GAPDH mRNA served as an internal control. The graphs represent the relative presence of specific PCR products in AL (black bars) and L-IFD (gray bars) mice. The NMDAR NR2B/2A subunit ratio in each area for AL and IFD mice is also shown. $\boldsymbol{D}$, Photomicrographs and immunohistochemical analyses of the NR2B expression pattern in the hippocampus of AL and L-IFD mice. The graphs represent the densitometric analysis of NR2B expression in the different areas of hippocampus ( $n=5$ animals per group in all tests). s luc, Stratum lucidum; mol, molecular layer; I mol, lacunosum moleculare layer; Molec, molecular layer; Lac mol, lacunosum moleculare layer; 0. D., optical density. ${ }^{*} p \leq 0.01 ;{ }^{* *} p \leq 0.01 ;{ }^{* * *} p \leq 0.001$.

Ro25-6981 administration decreases the facilitation of hippocampal synaptic plasticity in L-IFD mice L-IFD produced a marked increase in the expression of the NR2B subunit and in the NR2B/NR2A subunits ratio in hippocampus.
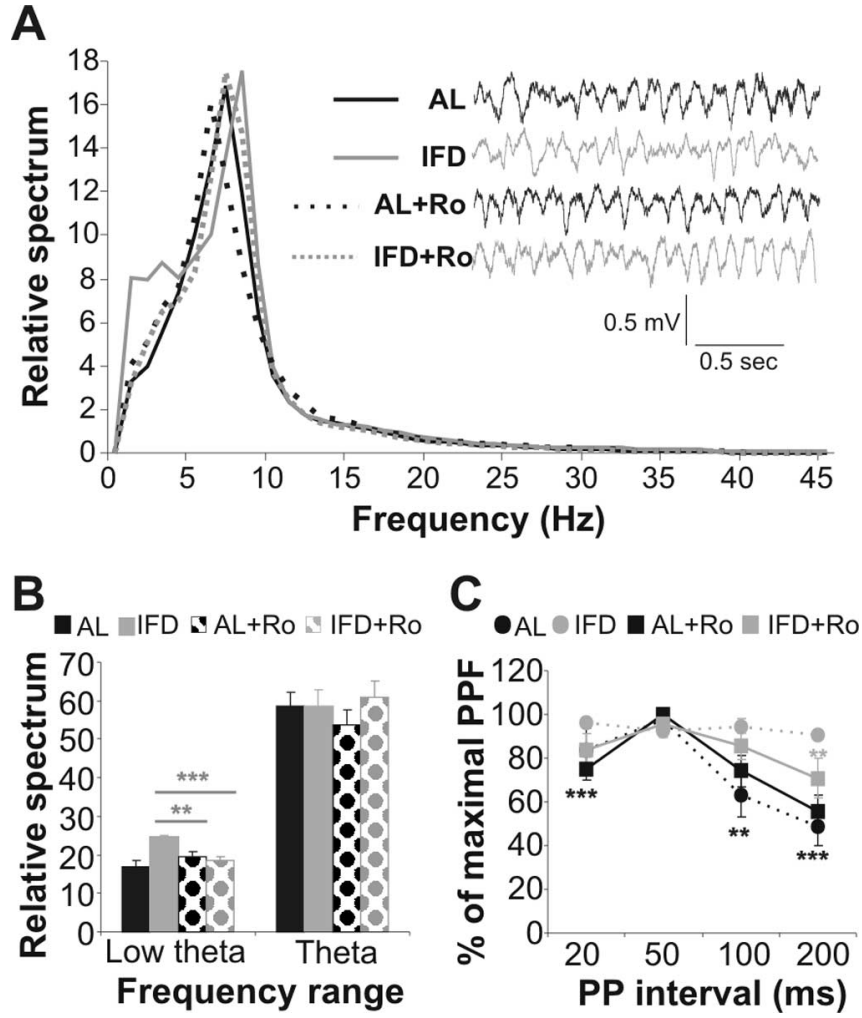

Figure 5. The NMDAR NR2B subunit antagonist, Ro25-6981 (Ro), partially restores the altered basal hippocampal activity induced by L-IFD. A, Averages of the relative power spectra of CA1 pyramidal layer field activity during exploratory behavior of AL and L-IFD mice 30 min after administration of either vehicle or Ro25-6981 (5 mg/kg, s.c.). Inset, Two-second samples of basal field activity recorded in AL and L-IFD mice under the same conditions (black for AL and gray for L-IFD mice). $\boldsymbol{B}$, Relative spectral power (mean \pm SEM) of low-theta and theta bands in AL and L-IFD mice 30 min after administration of either vehicle or Ro25-6981 (5 mg/kg, s.c.).C, Basal excitatory neurotransmission was measured using paired-pulse facilitation with interpulse intervals from 50 to $200 \mathrm{~ms}$ in the presence or absence of Ro25-6981. Bars represent the percentage of maximum paired-pulse facilitation as a function of interpulse interval in AL and L-IFD mice ( $n=6$ for each group). PP, Paired pulse. ${ }^{* *} p \leq 0.01 ;{ }^{* * *} p \leq 0.001$.

The NR2B subunit may be responsible for facilitating synaptic plasticity in young mice and NR2B-overexpressing transgenic mice. (Tang et al., 1999; Kohr et al., 2003; Barria and Malinow, 2005). Thus, we asked whether the increased NR2B expression in the hippocampus of mice subjected to L-IFD might be responsible for the facilitation of LTP in CA3-CA1 synapses. To assess this, we administered Ro25-6981 30 min before recording and 45 min before HFS delivery to either AL or L-IFD mice. Administration of the NR2B antagonist did not affect the synaptic plasticity evoked by up to three HFS trains in AL mice (Fig. 6). In contrast, Ro25-6981 administration in L-IFD mice reduced the LTP induced by one HFS train (Fig. $6 A, B)\left(F_{(20,3)}=3.95 ; p=\right.$ 0.023): $30 \mathrm{~min}$ after HFS, $137.62 \pm 4.87$ and $115.39 \pm 4.41 \%$ after vehicle and Ro25-6981 administration in L-IFD mice, respectively ( $p=0.006) ; 1 \mathrm{~h}$ after HFS, $141.84 \pm 0.84$ and $114.37 \pm$ $0.64 \%$ for vehicle and Ro25-6981 administration in L-IFD mice, respectively ( $p<0.001)$; and $2 \mathrm{~h}$ after HFS, $122.39 \pm 4.34$ and $109.24 \pm 3.24 \%$ for vehicle and Ro25-6981 administration in L-IFD mice, respectively $(p=0.11)$. In addition, Ro25-6981 administration to L-IFD mice did not produce any difference in LTP induced by three HFS trains with respect to L-IFD mice treated with vehicle. Moreover, the LTP after the two treatments was indistinguishable from that in AL mice (Fig. $6 C, D$ ). Together, these data indicate that the increase in expression of the 
A

$$
\text { - } A L \text { IFD } \square A L+R o=I F D+R o
$$
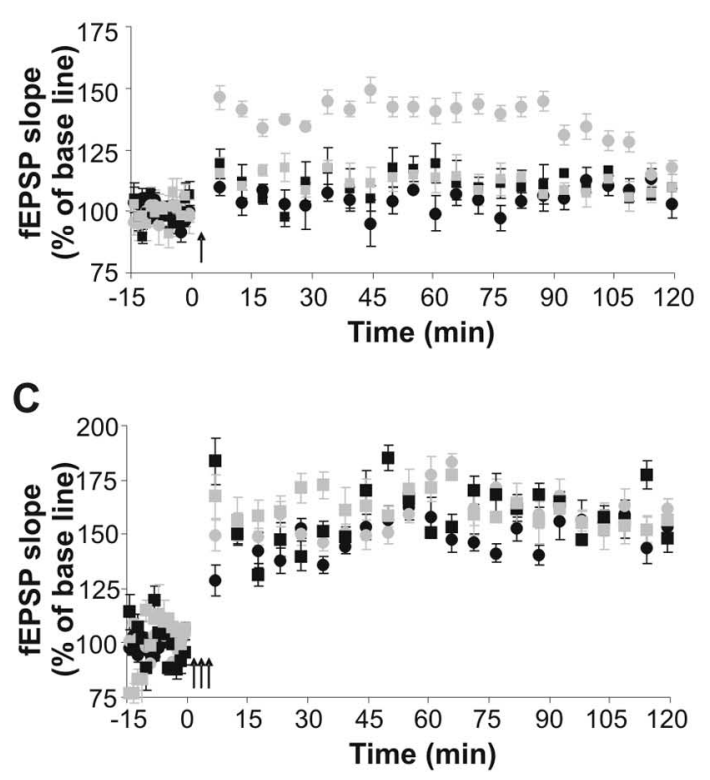

B

$\square A L=I F D=A L+R o=I F D+R o$
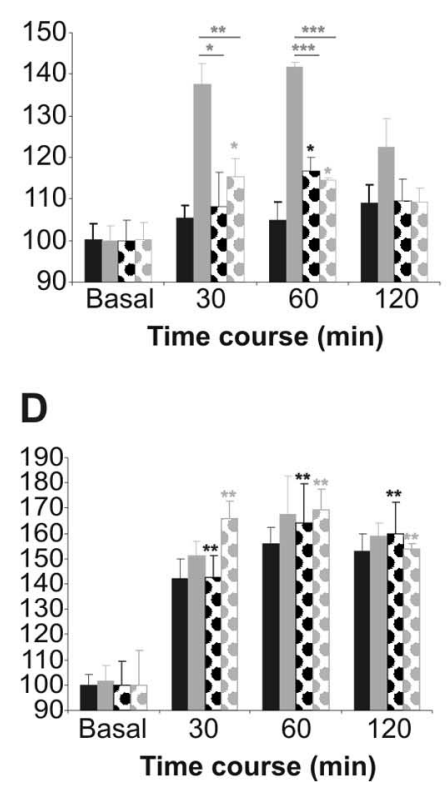

tion in the 15 min training protocol in L-IFD mice. After this extended training period, the sensitivity to Ro25-6981 was indistinguishable between AL and L-IFD mice. These results indicate that the enhanced learning in L-IFD mice depends on the expression of NR2B.

\section{Hippocampal NR2B mediated IFD- induced learning facilitation}

There is some controversy on the role of hippocampus and perirhinal cortex in ORM (for review, see Brown and Aggleton, 2001). To know the role of the two brain areas in ORM learning facilitation, we implanted bilateral cannulas in the hippocampus or in the perirhinal cortex of L-IFD mice (locations of infusion cannulas are illustrated in Fig. 7C). Ro256981 infusion through cannulas directed at the perirhinal cortex of L-IFD mice 5 min before the 5 min training protocol did not affect either short-term or long-term memory of ORM compared with values obtained after saline infusion $\left(F_{(15,2)}=\right.$ 37.2; $p<0.001$ ) (Fig. 7C). However, NR2B antagonist infusion in the hippocampus of L-IFD mice before the $5 \mathrm{~min}$ training protocol blocked both shortterm and long-term memories with respect to those infused with saline $\left(F_{(15,2)}\right.$ $=1.29 ; p=0.3)$. These data indicated that Figure 6. R025-6981 (Ro) reverses the facilitation of synaptic plasticity induced by L-IFD. A, A single HFS train [arrow; five pulses ( $200 \mathrm{~Hz}, 100 \mathrm{~ms}$ ) at a rate of 1/s] evokes an LTP at the CA3-CA1 synapse that lasts for up to $2 \mathrm{~h}$ in L-IFD mice (gray circles). Ro25-6981 administration (gray squares) reverses this effect but does not affect the same synapse in AL mice (black circles and squares). $\boldsymbol{B}$, Summary of percentage change in fEPSP slope (mean \pm SEM) at different times after a single HFS train in AL and L-IFD mice, in either the presence or absence of the specific NR2B antagonist. $C$, Three HFS trains (arrows) induce an indistinguishable LTP (lasting $>2 \mathrm{~h}$ ) in AL and L-IFD mice, in either the presence or absence of R025-6981. D, Summary of the percentage change in fEPSP slope (mean \pm SEM) at different times after three HFS trains in AL and L-IFD mice, in either the presence or absence of the specific NR2B antagonist ( $n=6$ for each group). ${ }^{*} p \leq 0.05 ;{ }^{* *} p \leq 0.01 ;{ }^{* * *} p \leq 0.001$.

NR2B subunit of NMDAR is necessary for the induction of LTP after one HFS train in L-IFD mice, although it is not required to induce LTP with three HFS trains.

\section{Blockage of NR2B reduces learning enhancement in L-IFD mice}

As we have shown, L-IFD facilitates the acquisition and consolidation of new information in mice. Furthermore, this treatment evokes changes in hippocampal activity and synaptic plasticity in an NR2B-dependent manner. Transgenic mice overexpressing the NR2B subunit of NMDAR in the forebrain display enhanced learning when compared with wild-type littermates (Tang et al., 1999). Hence, to determine whether L-IFD-facilitated learning was NR2B dependent, we used the eyeblink classical conditioning and ORM tests as learning paradigms. To determine the role of $\mathrm{NR} 2 \mathrm{~B}$ in the acquisition of the eyelid conditioning responses in L-IFD and AL mice, Ro25-6981 was injected $30 \mathrm{~min}$ before each classical conditioning session. Administration of the NR2B antagonist did not cause any noticeable effects on classical conditioning acquisition in AL mice (Fig. 7A), whereas in L-IFD mice, Ro25-6981 administration slowed classical conditioning acquisition to the pattern found in AL mice. We found statistically significant differences between the first and third sessions $(p<$ $0.05)$ when comparing vehicle and Ro25-6981 administration in L-IFD mice. To study the role of NR2B in ORM, we administered the NR2B antagonist 30 min before the training session. Ro256981 did not affect acquisition or consolidation of ORM in AL mice (Fig. 7B), whereas in L-IFD mice, Ro25-6981 administration blocked ORM learning in the 5 min training protocol $\left(F_{(15,2)}\right.$ $=1.44 \pm 0.26 ; p=0.26$ ) (Fig. $7 B$ ). In contrast, administration of the same drug did not change ORM acquisition and consolida-

overexpression of the NR2B subunit of NMDAR in the hippocampus is required for the learning facilitation in L-IFD mice.

\section{NR2B is necessary to facilitate consolidation in L-IFD mice}

As seen above in the classical conditioning and ORM tests, NR2B-containing NMDARs are necessary to facilitate learning in L-IFD mice. Hence, we wanted to know if the NR2B subunit contributes to consolidation of ORM in the 5 min training paradigm in L-IFD mice. To address this issue, we injected $5 \mathrm{mg} / \mathrm{kg}$ Ro25-6981 after the STM test, and $24 \mathrm{~h}$ later the retention of ORM was tested (as evidence of the effect on the consolidation process). When L-IFD mice were administered with vehicle, the discrimination indices during short-term and long-term memory tests were indistinguishable (short-term and long-term memory DI were $0.258 \pm 0.058$ and $0.179 \pm 0.02$, respectively; $p=0.279)$. In contrast, when the specific antagonist of NR2B was administered after the STM test, consolidation of ORM was blocked (short-term memory and long-term memory DI were $0.258 \pm 0.058$ and $-0.011 \pm 0.04$, respectively; $p=0.003$ ). These results suggest that processes dependent on NMDARs containing NR2B subunits could be responsible for the consolidation facilitation in L-IFD mice.

\section{Discussion}

As mean life expectancy extends, the quality of life available to the aged becomes an ever more important matter. The memory deficits commonly experienced in aging have been called ageassociated memory impairment (AAMI) (Crook et al., 1986). Although the various cognitive deficits included in AAMI are often subtle, they are nonetheless disturbing to those affected by them (Backman et al., 2001). Research on these age-related cog- 

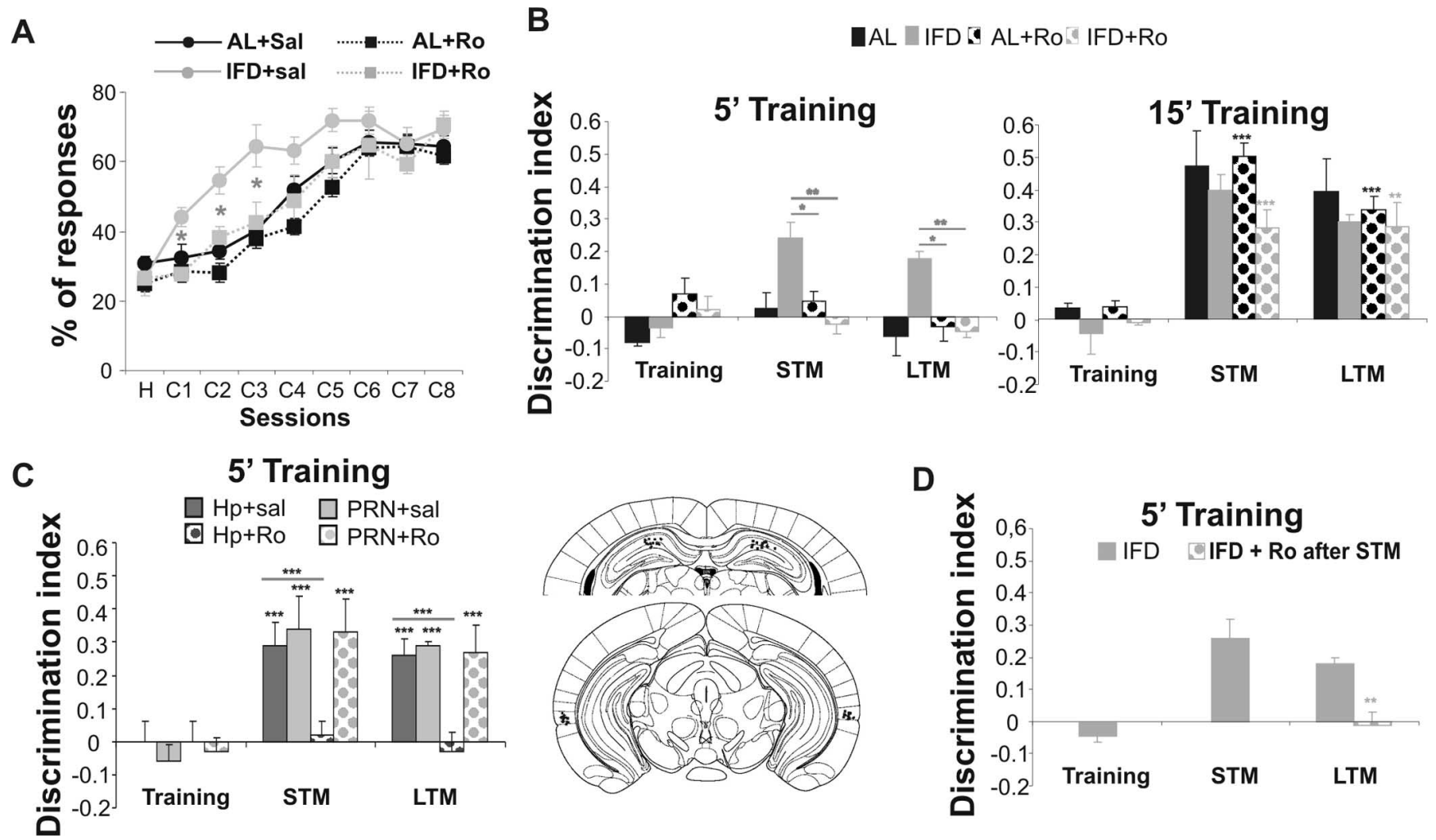

Figure 7. Ro25-6981 (Ro) reverses learning and consolidation facilitation induced by L-IFD. A, B, Administration of Ro25-6981 before each training session blocks the facilitation of trace eyeblink classical conditioning $(\boldsymbol{A})$ and object recognition memory $(\boldsymbol{B})$ induced by L-IFD. AL mice were not affected by Ro25-6981 administration. $\boldsymbol{C}$, The effects of Ro25-6951 infusion directly in hippocampus or perirhinal cortex of AL and L-IFD mice before a 5 min training session were evaluated for the object recognition memory test. Also, schematic representation of cannula localization in hippocampus (top) and perirhinal cortex (bottom) is shown. D. Administration of R025-6981 after STM test with a 5 min training in the object recognition memory paradigm blocks memory consolidation in L-IFD mice $\left(n=8\right.$ and 10 mice per group for eyeblink classical conditioning and ORM, respectively). ${ }^{*} p \leq 0.05 ;{ }^{* *} p \leq 0.01 ;{ }^{* * *} p \leq 0.001$. Hp, Hippocampus; PRN, perirhinal cortex; sal, saline.

nitive deficits and on drugs enhancing cognitive function may lead to effective treatments for both AAMI and for other, more severe cognitive impairments (McEntee and Larrabee, 2000).

CR restores synaptic plasticity and/or cognitive capabilities in aged animals (Idrobo et al., 1987; Ingram et al., 1987; Stewart et al., 1989; Pitsikas and Algeri, 1992; Pitsikas et al., 1992; Eckles et al., 1997; Eckles-Smith et al., 2000). However, the molecular bases underlying the amelioration of cognitive deficiencies induced by CR in aged animals are not understood. Here, we have demonstrated that mice submitted to L-IFD display improved cognitive functions, as well as an increased synaptic plasticity in hippocampal circuits, dependent on NMDARs containing NR2B subunits. The benefits of IFD in mature mice may be a consequence of modifications in the pattern of gene expression. Indeed, aging modifies the expression of many genes related to oxidative stress, inflammation (Lee et al., 2000; Park and Prolla, 2005), and neurotransmission. In many cases, the latter changes are counteracted by CR (Mattson et al., 2001). Here, we report that L-IFD causes an increase in the hippocampal expression of the NR2B subunit of the NMDAR in mature mice, mimicking the expression of NR2B found in young mice (Monyer et al., 1994; Sheng et al., 1994). These findings indicate that IFD could be a form of CR able to slow aging in rodents (Dubey et al., 1996; Finch and Morgan, 1997; Bordone and Guarente, 2005).

Genetic (Tsien et al., 1996; Tang et al., 1999; Cui et al., 2005) and pharmacological (Collingridge et al., 1983; Morris et al., 1986) approaches have established that NMDARs play a central role in synaptic plasticity and in learning and memory processes.
Although there are four NR2 subunits (A-D), the NR2A and NR2B subunits predominate in the forebrain. Each of the NR2 subunits imparts different functional characteristics to the NMDARs: NR2A-containing NMDARs have rapid kinetics and less-prolonged EPSPs than those containing NR2B (Monyer et al., 1994; Erreger et al., 2005). The NMDAR opening time is an important factor in the coincident detection of synaptic events (Bourne and Nicoll, 1993; Tsien, 2000), considering the response characterized by NR2B-rich receptors optimal for integration. During postnatal development (Monyer et al., 1994; Sheng et al., 1994) and in activity-dependent cortical development (Quinlan et al., 1999; Barth and Malenka, 2001), the NR2A-NR2B ratio changes, explaining the different decay kinetics of NMDARmediated synaptic responses (Hestrin, 1992; Flint et al., 1997).

The role of NMDAR subunits in synaptic plasticity remains unclear. It has been proposed that NR2A- and NR2B-type NMDARs induce LTP and long-term depression, respectively (Liu et al., 2004; Massey et al., 2004). In contrast, a role for NR2B subunits in LTP has been demonstrated in mice with NR2B overexpression in the forebrain (Tang et al., 1999; Wong et al., 2002; Cao et al., 2007) or by overexpression of NR2B subunits in brain slices (Barria and Malinow, 2005). Also, NR2B-dependent LTP was observed in mice with no or impaired NR2A signaling (Kiyama et al., 1998; Kohr et al., 2003) and when using NR2specific antagonists (Berberich et al., 2005). Our results show that NR2B is involved in LTP facilitation only when a single HFS train was used. The fact that LTP induced in AL and L-IFD mice by three trains of HFS was not affected by an NR2B-subunit antag- 
onist suggests that voltage-dependent $\mathrm{Ca}^{2+}$ channel and/or NR2A-containing NMDAR could be related to this process (Morgan and Teyler, 1999; Gruart et al., 2006). Therefore, the relative contribution of the NR2 subtypes in the induction of LTP in CA1 neurons could be determined by the temporal pattern of synaptic stimulation. Alternatively, our results could be explained by an alteration of the threshold of LTP induction caused by an increase in NR2B/2A ratio, rather than an indication of an absolute requirement of $\mathrm{NR} 2 \mathrm{~B}$ in LTP. Indeed, the observed NR2B-dependent increase in PPF and low-theta oscillation may contribute to the overall increase in excitability of these neurons and hence the reduced threshold of single HFS-induced LTP.

Our results show that the increase in the expression of the NR2B-containing NMDAR in hippocampus of L-IFD mice may be one of the many changes that occur in L-IFD brain that drives to a learning and memory enhancement. Mice overexpressing NR2B subunit in forebrain also display enhancement in LTP and learning with respect to control mice in healthy mice (Tang et al., 1999, 2001; White and Youngentob, 2004) as well as in old mice (Cao et al., 2007). Thus, the increase in expression and/or activity of NR2B subunits could improve cognitive capabilities in mice.

Electrophysiological properties of the hippocampus are also altered in L-IFD mice. Mouse hippocampal oscillation is in the theta band (5-9 Hz) (Vanderwolf, 1969). However, although the principal relative spectrum oscillation range of the theta rhythm in the hippocampus of L-IFD mice was similar to that of AL mice, an increase was observed in the relative spectrum $<5 \mathrm{~Hz}$ (lowtheta oscillation). Surprisingly, the activity of the NR2Bcontaining NMDARs was necessary for this increase within the low-theta band in L-IFD mice. Theta rhythm has been correlated with learning and memory (Klimesch, 1999; Kahana et al., 2001). However, little is known about the role of the low-theta rhythm in learning and memory processes. In humans, slow-wave-sleep rich oscillations occurring in the first half of the night have a positive influence on declarative memory consolidation and in a spatial learning task (Plihal and Born, 1997, 1999). Furthermore, the slow-wave-sleep period provokes coupling of neocortical and hippocampal activities, an event required for information transfer between the hippocampus and the neocortex, as occurs during memory consolidation (Sirota et al., 2003). Our results indicate that the increase in low-theta oscillation in L-IFD mice could extend the temporal window for consolidation when compared with AL mice, possibly resulting in an enhancement of memory processes. Furthermore, our results suggest that NMDARs, mainly those that contain the NR2B subunit, may be related to the genesis of such hippocampal oscillatory activity.

Basal hippocampal neurotransmission revealed by pairedpulse protocols is altered in L-IFD mice. Schaffer's collateralCA1 synapses in adult mice show maximum PPF in an interpulse interval of $\sim 50 \mathrm{~ms}$. This facilitation decreases as the interpulse interval increases. In contrast, L-IFD mice did not show any decrease in PPF in the assayed interpulse intervals. Moreover, the PPF of L-IFD mice were partially dependent on NR2B-subunitcontaining NMDARs. In L-IFD mice, this particular PPF may be explained by presynaptic mechanisms in which BDNF can modify glutamatergic basal transmission through TrkB and CaMKII phosphorylation (Crozier et al., 1999; Lin et al., 1999). In fact, BDNF and NR2B NMDAR subunits are overexpressed in CR mice (Mattson et al., 2004; Lee et al., 2002; this study). Other presynaptic mechanisms may also participate in this phenomenon; in fact, neurons of CR animals display alterations in calcium homeostasis that could modify neurotransmitter release (Matt- son et al., 2001). Ongoing experiments will elucidate these hypotheses.

There is some controversy about brain areas related to ORM. Recent reviews (Brown and Aggleton, 2001; Dere et al., 2007) argue that in ORM the perirhinal cortex is involved in object familiarization, whereas the hippocampus is involved in the relationship established between objects and space cues and in consolidation of the learned task. In the last years, the differential role of perirhinal cortex glutamate receptors in ORM has been established (Winters and Bussey, 2005; Barker et al., 2006a,b): kainate receptors are related to the fast-onset plasticity of the immediacy and novelty of the response and STM, whereas NMDARs are involved in the slow and long-lasting plasticity of familiar responses and LTM. On the other hand, the results of Rossato et al. (2007) and ourselves show that hippocampus is related to object familiarization (ORM acquisition in IFD and in young mice). Changes in firing properties of hippocampal CA1 neurons during associative learning (Múnera et al., 2001) suggest that the hippocampus encodes associative strength or predictive value. These properties could be enhanced in the presence of high expression of NMDAR containing NR2B subunit.

In summary, L-IFD mice show a clear facilitation in the acquisition and consolidation of new tasks when compared with AL mice. These findings could be attributed to a decrease in hippocampal aging, as witnessed by the upregulation of NR2B NMDAR subunit expression. Furthermore, NR2B expression probably confers the hippocampus of L-IFD mice with a better capacity for integrating information and for consolidation, probably as a result of changes in electric oscillatory patterns. Together, these data suggest that procedures that enhance the NR2B-containing NMDAR pathways could provide potential therapeutic strategies to diminish the cognitive impairment that occurs during normal aging or in disease.

\section{References}

Abel T, Lattal KM (2001) Molecular mechanisms of memory acquisition, consolidation and retrieval. Curr Opin Neurobiol 11:180-187.

Anson RM, Guo Z, de Cabo R, Iyun T, Rios M, Hagepanos A, Ingram DK, Lane MA, Mattson MP (2003) Intermittent fasting dissociates beneficial effects of dietary restriction on glucose metabolism and neuronal resistance to injury from calorie intake. Proc Natl Acad Sci USA 100:6216-6220.

Backman L, Small BJ, Wahlin A (2001) Aging and memory: cognitive and biological perspectives. In: Handbook of the psychology of aging (Birren JE, Schaie KW, eds), pp 349-377. San Diego: Academic.

Barger JL, Walford RL, Weindruch R (2003) The retardation of aging by caloric restriction: its significance in the transgenic era. Exp Gerontol 38:1343-1351.

Barker GR, Warburton EC, Koder T, Dolman NP, More JC, Aggleton JP, Bashir ZI, Auberson YP, Jane DE, Brown MW (2006a) The differential effects on recognition memory of perirhinal kainate and NMDA glutamate receptor antagonism: implication for underlying plasticity mechanisms. J Neurosci 26:3561-3566.

Barker GR, Bashir ZI, Brown MW, Warburton EC (2006b) A temporally distinct role for group I and group II metabotropic glutamate receptors in object recognition memory. Learn Mem 13:178-186.

Barria A, Malinow R (2005) NMDA receptor subunits composition controls synaptic plasticity by regulating binding to CamKII. Neuron 48:289-301.

Barth AL, Malenka RC (2001) NMDAR EPSC kinetics do not regulate the critical period for LTP at thalamocortical synapses. Nat Neurosci 4:235-236.

Berberich S, Punnakkal P, Jensen V, Pawlak V, Seeburg PH, Hvalby O, Kohr G (2005) Lack of NMDA receptor subtype selectivity for hippocampal long-term potentiation. J Neurosci 25:6907-6910.

Berrigan D, Perkins SN, Haines DC, Hursting SD (2002) Adult-onset calo- 
rie restriction and fasting delay spontaneous tumorigenesis in p53deficient mice. Carcinogenesis 23:817-822.

Bliss TV, Collingridge GL, Morris RG (2003) Introduction. Long-term potentiation and structure of the issue. Philos Trans R Soc Lond B Biol Sci 358:607-611.

Bordone L, Guarente L (2005) Calorie restriction, Sirt1 and metabolism: understanding longevity. Nat Rev Mol Cell Biol 6:298-305.

Bourne HR, Nicoll R (1993) Molecular machines integrate coincident synaptic signals. Cell 72:65-75.

Brown MW, Aggleton JP (2001) Recognition memory: what are the roles of the perirhinal cortex and hippocampus? Nat Rev Neurosci 2:51-61.

Cao X, Cui Z, Feng RZ, Tang Y-P, Qin Z, Mei B, Tsien JZ (2007) Maintenance of superior learning and memory function in NR2B transgenic mice during ageing. Eur J Neurosci 25:1815-1822.

Collingridge GL, Kehl S, McLennan H (1983) Excitatory amino acid in synaptic transmission in the Schaffer collateral-commissural pathways in the rat hippocampus. J Physiol (Lond) 334:33-46.

Crook T, Bartus RT, Ferris SH, Whitehouse P, Cohen GD, Gershon S (1986) Age-associated memory impairment: proposed diagnostic criteria and measures of clinical change. Report of a National Institute of Mental Health Work Group. Dev Neuropsychol 2:261-276.

Crozier RA, Black IB, Plummer MR (1999) Blockade of NR2B-containing NMDA receptors prevents BDNF enhancement of glutamatergic transmission in hippocampal neurons. Learn Mem 6:257-266.

Cui Z, Lindl KA, Mei B, Zhang S, Tsien JZ (2005) Requirement of NMDA receptor reactivation for consolidation and storage of nondeclarative taste memory revealed by inducible NR1 knockout. Eur J Neurosci 22:755-763.

Daoudal G, Debanne D (2003) Long-term plasticity of intrinsic excitability: learning rules and mechanisms. Learn Mem 10:456-465.

de los Santos-Arteaga M, Sierra-Domínguez SA, Fontanella GH, DelgadoGarcía JM, Carrion AM (2003) Analgesia induced by dietary restriction is mediated by the $\kappa$-opioid system. J Neurosci 23:11120-11126.

Dere E, Huston JP, De Souza Silva MA (2007) The pharmacology, neuroanatomy and neurogenetics of the one-trial object recognition in rodent. Neurosci Biobehav Rev 31:673-704.

Domínguez-del-Toro E, Rodríguez-Moreno A, Porras-García E, SánchezCampusano R, Blanchard V, Lavilla M, Bohme GA, Benavides J, DelgadoGarcía JM (2004) An in vitro and in vivo study of early deficits in associative learning in transgenic mice that over-express a mutant form of human APP associated with Alzheimer's disease. Eur J Neurosci 20:1945-1952.

Dubey A, Forster MJ, Lal H, Sohal RS (1996) Effect of age and caloric intake on protein oxidation in different brain regions and on behavioral functions of the mouse. Arch Biochem Biophys 333:189-197.

Eckles KE, Dudek EM, Bickford PC, Browning MD (1997) Amelioration of age-related deficits in the stimulation of synapsin phosphorylation. Neurobiol Aging 18:213-217.

Eckles-Smith K, Clayton D, Bickford P, Browning MD (2000) Caloric restriction prevents age-related deficits in LTP and in NMDA receptor expression. Brain Res Mol Brain Res 78:154-162.

Erreger K, Dravid SM, Banke TG, Wyllie DJ, Traynelis SF (2005) Subunitspecific gating controls rat NR1/NR2A and NR1/NR2B NMDA channel kinetics and synaptic signalling profiles. J Physiol (Lond) 563:345-358.

Finch CE, Morgan TE (1997) Food restriction and brain aging. In: Advances in cell aging and gerontology, $\mathrm{Vol}$ 2, The aging brain (Mattson MP, Geddes JW, eds), pp 279-297. Greenwich, CT: JAI.

Flint AC, Maisch US, Weishaupt JH, Kriegstien AR, Monyer H (1997) NR2A subunit expression shortens NMDA receptor synaptic currents in developing neocortex. J Neurosci 17:2469-2476.

Gruart A, Muñoz MD, Delgado-García JM (2006) Involvement of the CA3CA1 synapse in the acquisition of associative learning in behaving mice. J Neurosci 26:1077-1087.

Heilbronn LK, Ravussin E (2003) Calorie restriction and aging: review of the literature and implications for studies in humans. Am J Clin Nutr 78:361-369.

Hestrin S (1992) Developmental regulation of NMDA receptor-mediated synaptic currents at a central synapse. Nature 357:686-689.

Huerta PT, Sun LD, Wilson MA, Tonegawa S (2000) Formation of temporal memory requires NMDA receptors within CA1 pyramidal neurons. Neuron 25:473-480.

Hursting SD, Lavigne JA, Berrigan D, Perkins SN, Barrett JC (2003) Calorie restriction, aging, and cancer prevention: mechanisms of action and applicability to humans. Annu Rev Med 54:131-152.

Husi H, Ward MA, Choudhary JS, Blackstock WP, Grant SG (2000) Proteomic analysis of NMDA receptor-adhesion protein signaling complexes. Nat Neurosci 3:661-669.

Idrobo F, Nandy K, Mostofsky DI, Blatt L, Nandy L (1987) Dietary restriction: effects on radial maze learning and lipofuscin pigment deposition in the hippocampus and frontal cortex. Arch Gerontol Geriatr 6:255-262.

Inda MC, Delgado-García JM, Carrión A (2005) Acquisition, consolidation, reconsolidation, and extinction of eyelid conditioning response require de novo protein synthesis. J Neurosci 25:2070-2080.

Ingram DK, Weindruch R, Spangler EL, Freeman JR, Walford RL (1987) Dietary restriction benefits learning and motor performance of aged mice. J Gerontol 42:78-81.

Ingram DK, Anson RM, de Cabo R, Mamczarz J, Zhu M, Mattison J, Lane MA, Roth GS (2004) Development of calorie restriction mimetics as a prolongevity strategy. Ann NY Acad Sci 1019:412-423.

Kahana MJ, Seelig D, Madsen JR (2001) Theta returns. Curr Opin Neurobiol 11:739-744.

Kandel ER (2001) The molecular biology of memory storage: a dialogue between genes and synapses. Science 294:1030-1038.

Kim MJ, Dunah AW, Wang YT, Sheng M (2005) Differential roles of NR2Aand NR2B-containing NMDA receptors in Ras-ERK signaling and AMPA receptor trafficking. Neuron 46:745-760.

Kiyama Y, Manabe T, Sakimura K, Kawakami F, Mori H, Mishina M (1998) Increased thresholds for long-term potentiation and contextual learning in mice lacking the NMDA-type glutamate receptor $\varepsilon 1$ subunit. J Neurosci 18:6704-6712.

Klimesch W (1999) EEG alpha and theta oscillations reflect cognitive and memory performance: a review and analysis. Brain Res Rev 29:169-195.

Kohr G, Jensen V, Koester HJ, Mihaljevic AL, Utvik JK, Kvello A, Ottersen OP, Seeburg PH, Sprengel R, Hvalby O (2003) Intracellular domains of NMDA receptor subtypes are determinants for long-term potentiation induction. J Neurosci 23:10791-10799.

Lane MA, Ingram DK, Roth GS (1999) Calorie restriction in nonhuman primates: effects on diabetes and cardiovascular disease risk. Toxicol Sci 52:41-48.

Lee CK, Weindruch R, Prolla TA (2000) Gene-expression profile of the ageing brain in mice. Nat Genet 25:294-297.

Lee J, Seroogy KB, Mattson MP (2002) Dietary restriction enhances neurotrophin expression and neurogenesis in the hippocampus of adult mice. J Neurochem 80:539-547.

Lin SJ, Defossez PA, Guarente L (2000) Requirement of NAD and SIR2 for life-span extension by calorie restriction in Saccharomyces cerevisiae. Science 289:2126-2128.

Lin SY, Wu K, Len GW, Xu JL, Levine ES, Suen PC, Mount HT, Black IB (1999) Brain-derived neurotrophic factor enhances association of protein tyrosine phosphatase PTP1D with the NMDA receptor subunit NR2B in the cortical postsynaptic density. Brain Res Mol Brain Res $70: 18-25$

Liu L, Wong TP, Pozza MF, Lingenhoehl K, Wang Y, Sheng M, Auberson YP, Wang YT (2004) Role of NMDA receptor subtypes in governing the direction of hippocampal synaptic plasticity. Science 304:1021-1024.

Loftis JM, Janawsky A (2003) The N-methyl-D-aspartate subunit NR2B: localization, functional properties regulation, and clinical implications. Pharmacol Ther 97:55-85.

Masoro EJ (2000) Caloric restriction and aging: an update. Exp Gerontol 35:299-305.

Massey PV, Johnson BE, Moult PR, Auberson YP, Brown MW, Molnar E, Collingridge GL, Bashir ZI (2004) Differential roles of NR2A- and NR2B-containing NMDA receptors in cortical long-term potentiation and long-term depression. J Neurosci 24:7821-7828.

Mattson MP, Duan W, Lee J, Guo Z (2001) Suppression of brain aging and neurodegenerative disorder by dietary restriction and environmental enrichment: molecular mechanisms. Mech Ageing Dev 122:757-778.

Mattson MP, Duan W, Guo Z (2003) Meal size and frequency affect neuronal plasticity and vulnerability to disease: cellular and molecular mechanisms. J Neurochem 84:417-431.

Mattson MP, Maudsley S, Martin B (2004) A neural signaling triumvirate that influences ageing and age-related disease: insulin/IGF-1, BDNF and serotonin. Ageing Res Rev 3:445-464. 
McEntee WJ, Larrabee GJ (2000) Age-associated memory impairment. Curr Treat Options Neurol 2:73-80.

Monyer H, Burnashev N, Laurie DJ, Sakmann B, Seeburg PH (1994) Developmental and regional expression in the rat brain and functional properties of four NMDA receptors. Neuron 12:529-540.

Morgan SL, Teyler TJ (1999) VDCCs and NMDARs underlie two forms of LTP in CA1 hippocampus in vivo. J Neurophysiol 82:736-740.

Morris RGM, Anderson E, Lynch G, Baudry M (1986) Selective impairment of learning and blockade of long-term potentiation by NMDA receptor antagonist, AP5. Nature 319:774-776.

Múnera A, Gruart A, Muñoz MD, Fernández-Más R, Delgado-García JM (2001) Discharge properties of identified CA1 and CA3 hippocampus neurons during unconditioned and conditioned eyelid responses in cats. J Neurophysiol 6:2571-2582.

Park SK, Prolla TA (2005) Lessons learned from gene expression profile of aging and caloric restriction. Ageing Res Rev 4:55-65.

Paxinos G, Franklin KB (2001) The mouse brain in sterotoxic coordinates. London: Academic.

Pitsikas N, Algeri S (1992) Deterioration of spatial and non-spatial reference and working memory in aged rats: protective effects of life-long caloric restriction. Neurobiol Aging 13:369-373.

Pitsikas N, Garofalo P, Zanotti A, Algeri S (1992) Effect of lifelong hypocaloric diet on discrete memory of the senescent rat. Aging 3:147-152.

Plihal W, Born J (1997) Effects of early and late nocturnal sleep on declarative and procedural memory. J Cogn Neurosci 9:534-547.

Plihal W, Born J (1999) Effects of early and late nocturnal sleep on priming and spatial memory. Psychophysiology 36:571-582.

Quinlan EM, Philpot BD, Huganir RL, Bear MF (1999) Rapid, experience dependent expression of synaptic NMDA receptors in visual cortex in vivo. Nat Neurosci 2:352-357.

Rosenzweig EP, Barnes CA (2003) Impact of aging on hippocampal function: plasticity, network dynamics, and cognition. Prog Neurobiol 69:143-179.

Rossato JI, Bevilaqua LRM, Myskiw JC, Medina JH, Izquierdo I, Cammarota M (2007) On the role of hippocampal protein synthesis in the consolidation and reconsolidation of object recognition memory. Learn Mem $14: 36-46$

Roth GS, Mattison JA, Ottinger MA, Chachich ME, Lane MA, Ingram DK (2004) Aging in rhesus monkeys: relevance to human health interventions. Science 305:1423-1426.

Sakimura K, Kutsuwada T, Ito I, Manabe T, Takayama C, Kushiya E, Yagi T, Aizawa S, Inoue Y, Sugiyama H (1995) Reduced hippocampal LTP and spatial learning in mice lacking NMDA receptor $\varepsilon 1$ subunit. Nature 373:151-155.

Sheng M, Cummings J, Roldan LA, Jan YN, Jan LY (1994) Changing subunit composition of heteromeric NMDA receptors during development of rat cortex. Nature 368:144-147.

Sirota A, Csicsvari J, Buhl D, Buzsáki G (2003) Communication between neocortex and hippocampus during sleep in rodents. Proc Natl Acad Sci USA 100:2065-2069.
Squire LR, Zola-Morgan S (1991) The medial temporal lobe memory system. Science 253:1380-1386.

Stern JS, Gades MD, Wheeldon CM, Borchers AT (2001) Calorie restriction in obesity: prevention of kidney disease in rodents. J Nutr 131: 913S-917S

Stewart J, Mitchell J, Kalant N (1989) The effects of life-long food restriction on spatial memory in young and aged Fischer 344 rats measured in the eight-arm radial and the Morris water mazes. Neurobiol Aging 10:669-675.

Tang YP, Shimizu E, Dube GR, Rampon C, Kerchner GA, Zhuo M, Liu G, Tsien JZ (1999) Genetic enhancement of learning and memory in mice. Nature 401:25-27.

Tang YP, Wang H, Feng R, Kyin M, Tsien JZ (2001) Differential effects of enrichment on learning and memory function in NR2B transgenic mice. Neuropharmacology 41:779-790.

Tsien JZ (2000) Linking Hebb's coincidence-detection to memory formation. Curr Opin Neurobiol 10:266-273.

Tsien JZ, Huerta PT, Tanegawa S (1996) The essential role of hippocampal CA1 NMDA receptor-dependent synaptic plasticity in spatial memory. Cell 87:1327-1338.

Valenzuela-Harrington M, Gruart A, Delgado-Garcia JM (2007) Contribution of NMDA receptor NR2B subunit to synaptic plasticity during associative learning in behaving rats. Eur J Neurosci 25:830-836.

Vanderwolf CH (1969) Hippocampal electrical activity and voluntary movement in the rat. Electroencephalogr Clin Neurophysiol 26:407-418.

Verdery RB, Walford RL (1998) Changes in plasma lipids and lipoproteins in humans during a 2-year period of dietary restriction in Biosphere 2. Arch Intern Med 158:900-906

Walford RL, Harris SB, Gunion MW (1992) The calorically restricted lowfat nutrient-dense diet in Biosphere 2 significantly lowers blood glucose, total leukocyte count, cholesterol, and blood pressure in humans. Proc Natl Acad Sci USA 89:11533-11537.

Walford RL, Mock D, Verdery R, MacCallum T (2002) Calorie restriction in Biosphere 2: alterations in physiologic, hematologic, hormonal, and biochemical parameters in humans restricted for a 2-year period. J Gerontol A Biol Sci Med Sci 57:B211-B224.

Walikonis RS, Jensen ON, Mann M, Provance Jr DW, Mercer JA, Kennedy MB (2000) Identification of proteins in the postsynaptic density fraction by mass spectrometry. J Neurosci 20:4069-4080.

Weindruch R, Walford RL (1988) The retardation of aging and disease by dietary restriction. Springfield, IL: Charles C. Thomas.

White TL, Youngentob SL (2004) The effect of NMDA-NR2B receptor subunit over-expression on olfactory memory task performance in the mouse. Brain Res 1021:1-7.

Winters BD, Bussey TJ (2005) Glutamate receptors in perirhinal cortex mediate encoding, retrieval, and consolidation of object recognition memory. J Neurosci 25:4243-4251.

Wong RW, Setou M, Teng J, Takei Y, Hirokawa N (2002) Overexpression of motor protein KIF17 enhances spatial and working memory in transgenic mice. Proc Natl Acad Sci USA 99:14500-14505. 